\title{
P059. Neuropsychological assessment in a case of medication-overuse headache associated with probable executive deficit
}

\author{
Alessandra Sansalone, Amerigo Costa, Rosario lannacchero* \\ From Abstracts from the 1st Joint ANIRCEF-SISC Congress \\ Rome, Italy. 29-31 October 2015
}

\section{Background}

Recent studies attest to a relationship between medication-overuse headache $(\mathrm{MOH})$ and cognitive impairment, especially regarding visual memory, verbal memory, processing speed, decision-making and attention, which constitute the executive function (EF) [1]. EF impairment in $\mathrm{MOH}$ patients may relate to frontal cortex hypo-metabolism [2]. Evidence about this relationship is conflicting [3]. We present the case of a $\mathrm{MOH}$ patient showing, at a clinical-psychological evaluation, cognitive issues that prompted a neuropsychological assessment.

\section{Materials and methods}

A 52-year-old woman with a 15-year clinical history of chronic migraine (CM) came to our Center in September 2014. She presented with daily migraine and continuous use of non-steroidal anti-inflammatory drugs (NSAIDs). Brain magnetic resonance imaging (RMI) showed an occipital arachnoid cyst. Venous magnetic resonance angiography (vMRA) was negative. At the headache assessment, the neurologist diagnosed probable $\mathrm{MOH}$ $(\mathrm{pMOH})$. The clinical-psychological evaluation showed significant levels of anxiety (Zung Self-Rating Anxiety Scale $=45)$ and self-referred cognitive issues, especially regarding memory, attention and focusing. After three months, $\mathrm{MOH}$ diagnosis was confirmed. Given the cognitive symptoms, even though a preliminary assessment showed normal score (Cognitive Failure Questionnaire = 38), we performed a deeper neuropsychological assessment. We first assessed general cognitive efficiency (Mini Mental State Examination; Raven Progressive Matrices;

\footnotetext{
*Correspondence: centrocefaleeaopc@gmail.com

Center for Headache and Adaptive Disorders, Unit of Neurology, Department of Neuroscience and Sense Organs, Azienda Ospedaliera "Pugliese-Ciaccio",
} Catanzaro, Italy

\section{Conclusions}

The detected EF impairment could relate with behavioral aspects relevant to $\mathrm{MOH}$, such as, non-adherence and compulsive medication use. The patient could benefit from psychological interventions complementary to the medical headache therapy: psycho-education might improve $\mathrm{MOH}$ management; problem-solving training might enhance health management strategies seeking; relaxation training might improve health-related anxiety. Functional neuroimaging is required to investigate the brain areas activity.

Written informed consent to publish was obtained from the patient(s) 


\section{References}

1. de Araújo CM, Barbosa Ig, Lemos SMA, Domingues RB, Teixeira AL: Cognitive impairment in migraine: a systematic review. Dement Neuropsychol 2012, 6(2):74-79.

2. Biagianti B, Grazzi L, Gambini O, Usai S, Muffatti R, Scarone S, Bussone G: Orbitofrontal dysfunction and medication overuse in patients with migraine. Headache 2012, 52(10):1511-1519.

3. Suhr JA, Seng EK: Neuropsychological functioning in migraine: clinical and research implications. Cephalalgia 2012, 32(1):39-54.

doi:10.1186/1129-2377-16-S1-A154

Cite this article as: Sansalone et al:: P059. Neuropsychological assessment in a case of medication-overuse headache associated with probable executive deficit. The Journal of Headache and Pain 2015 16(Suppl 1):A154

\section{Submit your manuscript to a SpringerOpen ${ }^{\mathcal{O}}$ journal and benefit from:}

- Convenient online submission

- Rigorous peer review

- Immediate publication on acceptance

- Open access: articles freely available online

- High visibility within the field

- Retaining the copyright to your article

Submit your next manuscript at $\gg$ springeropen.com 